\title{
A genome wide SNP genotyping study in the Tunisian population: specific reporting on a subset of common breast cancer risk loci
}

Yosr Hamdi ${ }^{*}$, Mariem Ben Rekaya', Shan Jingxuan², Majdi Nagara', Olfa Messaoud', Amel Benammar Elgaaied ${ }^{3}$, Ridha Mrad', Lotfi Chouchane ${ }^{2}$, Mohamed Samir Boubaker ${ }^{1}$, Sonia Abdelhak¹, Hamouda Boussen ${ }^{5}$ and Lilia Romdhane ${ }^{1,6}$

\begin{abstract}
Background: Breast cancer is the most common cancer in women worldwide. Around $50 \%$ of breast cancer familial risk has been so far explained by known susceptibility alleles with variable levels of risk and prevalence. The vast majority of these breast cancer associated variations reported to date are from populations of European ancestry. In spite of its heterogeneity and genetic wealth, North-African populations have not been studied by the HapMap and the 1000Genomes projects. Thus, very little is known about the genetic architecture of these populations.

Methods: This study aimed to investigate a subset of common breast cancer loci in the general Tunisian population and to compare their genetic composition to those of other ethnic groups. We undertook a genomewide haplotype study by genotyping 135 Tunisian subjects using the Affymetrix 6.0-Array. We compared Tunisian allele frequencies and linkage disequilibrium patterns to those of HapMap populations and we performed a comprehensive assessment of the functional effects of several selected variants.

Results: Haplotype analyses showed that at risk haplotypes on 2p24, 4q21, 6q25, 9q31, 10q26, 11p15, 11 q13 and $14 q 32$ loci are considerably frequent in the Tunisian population (> 20\%). Allele frequency comparison showed that the frequency of rs13329835 is significantly different between Tunisian and all other HapMap populations. LDblocks and Principle Component Analysis revealed that the genetic characteristics of breast cancer variants in the Tunisian, and so probably the North-African populations, are more similar to those of Europeans than Africans. Using eQTI analysis, we characterized rs9911630 as the most strongly expression-associated SNP that seems to affect the expression levels of BRCA1 and two long non coding RNAs (NBR2 and LINC008854). Additional in-silico analysis also suggested a potential functional significance of this variant.

Conclusions: We illustrated the utility of combining haplotype analysis in diverse ethnic groups with functional analysis to explore breast cancer genetic architecture in Tunisia. Results presented in this study provide the first report on a large number of common breast cancer genetic polymorphisms in the Tunisian population which may establish a baseline database to guide future association studies in North Africa.
\end{abstract}

Keywords: Breast cancer susceptibility, Haplotype analysis, Population genetics, Functional analysis

\footnotetext{
* Correspondence: yosr.hamdi.82@gmail.com

${ }^{1}$ Laboratory of biomedical genomics and oncogenetics, Institut Pasteur de

Tunis, Université Tunis El Manar, 13, Place Pasteur BP 74, 1002 Tunis,

Belvédère, Tunisie

Full list of author information is available at the end of the article
}

(c) The Author(s). 2018 Open Access This article is distributed under the terms of the Creative Commons Attribution 4.0 International License (http://creativecommons.org/licenses/by/4.0/), which permits unrestricted use, distribution, and reproduction in any medium, provided you give appropriate credit to the original author(s) and the source, provide a link to the Creative Commons license, and indicate if changes were made. The Creative Commons Public Domain Dedication waiver (http://creativecommons.org/publicdomain/zero/1.0/) applies to the data made available in this article, unless otherwise stated. 


\section{Background}

Breast cancer is a complex disease with a strong heritable component. Numerous genetic, hormonal and external environmental factors are involved in breast cancer etiology [1].

Currently, half of the inherited susceptibility to breast cancer is explained by a combination of high, intermediate, and low-risk alleles [2]. Rare high risk alleles such as BRCA1 [3, 4], BRCA2 [5, 6], TP53 [7], STK11, PTEN and $C D H 1$ explain approximately $20-30 \%$ of the inherited susceptibility, intermediate-risk alleles in genes such as CHEK2, ATM, BRIP1(FANCJ) [8-10] and PALB2 (FAN $C N)$ [11-15] explain an additional 5\%, while common lower penetrance alleles explain approximately $16 \%$ of the breast cancer risk [16-23]. Thus, many additional loci remain to be identified [24-26].

In North Africa, breast cancer is the most common cancer among women, representing 25 to $35 \%$ of all female cancers [27]. Compared to Western countries, the incidence of breast cancer in North-African countries ( $\mathrm{Tu}$ nisia, Algeria, Morocco, Libya and Egypt) is lower [28, 29]. However, it is reported that breast cancer is more aggressive in North Africa than in Western countries with notably large proportions of young patients [30-32].

These large differences are mainly explained by different genetic architectures between populations. Initiatives such as the international HapMap and the 1000 Genomes projects $[33,34]$ provided an unprecedented opportunity to systematically analyze genetic differences and similarities between human populations from European, Asian, and Sub-Saharan origins. It is well known that any given haplotype frequency may differ from one population to another because of different Linkage Disequilibrium (LD) structures and variable genetic variant frequencies among populations [33]. Analysing differences in genetic loci patterns between ethnicities may help to decode the biological mechanisms by which the risk associated variant at a susceptibility locus causes breast cancer [34-37]. Indeed, the high level of haplotype diversity in African populations may facilitate finemapping of causal variants that underlie disease associations [38-40]. For instance, fine mapping in the AfricanAmerican population contributed to the localization of a causal variant in FGFR2, a low penetrance breast cancer susceptibility locus [41]. Therefore, studying other African populations may bring new insights on breast cancer genetic knowledge.

The Tunisian population (TUN), is a heterogeneous and admixed population from African and European origins [42]. The particular structure of the Tunisian population is also due to a relatively high rate of consanguinity that has an impact on the incidence of monogenic diseases such as those predisposing to cancer [43]. Despite its genetic wealth, few breast cancer genetic studies have been performed in the TUN population such as those that focused on the identification of the mutational spectrum of BRCA1 and BRCA2 [44, 45]. Thus, little is known about the involvement of other genes of high and moderate penetrance and much less for common variants regarding their frequencies, correlation coefficients and association with breast cancer risk in Tunisia. Indeed, a study investigating breast cancer risk in Tunisia associated with 9 risk SNPs has been performed [46]. Because of the limited number of breast cancer risk SNPs that have been investigated so far in the Tunisian population, this current study aim to extend the number of common genetic variants investigated in the general healthy Tunisian population and to compare their characteristics between different ethnic groups.

\section{Methods}

\section{Study population and DNA extraction}

A total of 165 healthy unrelated Tunisian individuals originating from different regions of Tunisia (North, Center and South) have been recruited from the department of Radiation Oncology of Sousse Hospital (Sousse, Tunisia) and from Pasteur Institute (Tunis, Tunisia). Males (45\%) and females (55\%) (Reflecting the sex ratio of the general Tunisian population) having no evidence of any personal or familial history of breast cancer or any other known malignancies have been included. Participants had a mean age of $48 \pm 10$ years. All individuals signed informed consents. Ethical approval according to the Declaration of Helsinki Principles was obtained from the biomedical ethics committee of Pasteur Institute of Tunis (PV09/06, IRB\# 0000000044).

Genomic DNA was extracted from peripheral blood leukocytes by a "Salting-out" procedure [47]. $5 \mathrm{ml}$ of blood was mixed with Triton lysis buffer. Leukocytes were spun down and washed with $\mathrm{H} 2 \mathrm{O}$. The pellet was incubated with proteinase $\mathrm{K}$ and subsequently salted out using a saturated $\mathrm{NaCl}$ solution. Precipitated proteins were removed by centrifugation. The DNA pellet was dissolved in $400 \mu \mathrm{l}$ of sterile distilled water. DNA concentration and quality were analyzed by the Nanodrop 2000 .

\section{Genotyping and quality control steps}

The initial individual subset was 165 healthy Tunisians. We first performed a sorting step based on the DNA quality and concentration. At this step we excluded 30 individuals due to their bad DNA quality and thus a total of 135 samples have been successfully genotyped. Standard quality control measures were applied across all genotyped samples. For quality control purposes, 2\% of samples were duplicated.

Genome-wide scanning was applied with Affymetrix Genome-Wide Human SNP Array 6.0 following the 
manufacturer's protocol. After genotype calling using the R package CRLMM [48], the total SNPs on Affymetrix array were subjected to quality control. 291,195 SNPs have been excluded because of low chip design scores and low call frequency $(<95 \%)$. In fact, the Affymetrix array 6.0 has been designed based on HapMap data providing a lower level of genome coverage in population from African ancestry than European and Asian populations. 80.624 SNPs have been excluded because of low minor allele frequency $(<5 \%)$ and evidence of deviation from Hardy Weinberg Equilibrium. The final SNP set included 534,781 SNPs for genome-wide analysis.

In addition, genotype data of the selected breast cancer polymorphisms were also extracted for populations from the HapMap3 project including Europeans (Utah residents with European ancestry (CEU) and Toscans in Italy (TSI)), Asians (Han Chinese in Beijing (CHB), Chinese in Metropolitan Denver (CHD), Gujarati Indians in Houston (GIH) and Japanese in Tokyo (JPT)), Africans (Yoruba in Nigeria (YRI), Maasai in Kinyawa (MKK), Luhya in Kenya (LWK) and African ancestry in Southwest USA (ASW)) as well as Mexicans living in Los Angeles (MEX).

Minor allele frequency (MAF) and departure from Hardy Weinberg equilibrium (HWE) of markers at breast cancer loci were estimated using the SNPassoc R package [49].

\section{Genotyping data analysis}

To assess population stratification, a multidimensional scaling analysis (MDS) was performed as implemented in PLINK 1.07 on the identity-by-state (IBS) matrix of the samples. PLINK was used to carry out the genome-wide analysis of the autosomal SNPs and to perform permutation test to examine the stability of $p$-values. Genotype distributions and pairwise comparisons were evaluated by the chi-square test using a p-value threshold of 0.05 .

\section{LD analysis}

Genotype and marker data files were loaded into the Haploview software (http://www.broad.mit.edu/mpg/ haploview/) [50]. The $\mathrm{r}^{2}$ statistics of the Haploview4.0 software were used for haplotype block identification by calculating the pairwise LD for each sequence variant pair for the 135 genotyped subjects as well as those from the HapMap project. The Gabriel et al. algorithm of block definition was selected [51]. The 'Tagger' program from the same software was used to select a minimal set of tagSNPs as if all alleles are captured (frequency $>5 \%$ ) and was correlated at an $\mathrm{r}^{2}$ greater than a 0.8 threshold.

\section{Haplotype estimation}

Haplotype phasing and frequency estimations were performed using Phase 2.1.1 software [52]. This program estimates haplotype frequencies with a Bayesian-based algorithm. Haplotypes were phased using SNPs with $\mathrm{MAF} \geq 5 \%$.

\section{In silico assessment of functional effects}

To predict potential functional impact of selected SNPs, we used web-based algorithms with default settings: Align-GVGD (http://agvgd.iarc.fr/) [53] and SIFT (http:// sift.bii.a-star.edu.sg/) mainly based on phylogenetic information and biochemical differences between the reference and variant amino acid for assessing the functional effects of missense variants [54] and the RegulomeDB database (www.regulomedb.org) to evaluate the functional impact of regulatory variants [55]. Publicly available genomic data was also used to annotate variants that showed high RegulomeDB scores. The following regulatory features were obtained for different cell types including breast cancer cells from ENCODE and NIH Roadmap Epigenomics data through the UCSC Genome Browser: Transcription factor ChiP-seq data, altered motifs, eQTL, histone modifications and Chromatin Hidden Markov Modelling (Chrom HMM) states.

In order to identify variants that alter micro RNA binding sites, we used the latest miRBase release (v20, June 2013) (http://www.mirbase.org/), the primary microRNA sequence repository that contains 24,521 microRNA loci from 206 species.

\section{eQTL analysis}

rs9911630-BRCA1 was tested for correlation with nearby gene expression using the eQTL database GENe Expression VARiation (Genevar) from Sanger institute platform [56]. Genotypes and expression data within this database are derived from 3 cell types (fibroblast, lymphoblastoid cell line and T cell) and 3 tissue types (166 adipose, 156 lymphoblastoid cell line and 160 skin) from healthy female twins [56]. eQTL data is available for 8 different populations from European, Asian and African origins. Differences in the distribution of normalized expression levels between genotypes were compared using a linear regression model. To avoid false positive associations due to multiple tests, we set a significance threshold of $p<10^{-3}$ and assessed significance using 10,000-folds permutation.

We also used the Genotype-Tissue Expression (GTEx) database (http://gtexportal.org) in order to assess the correlation between selected breast cancer associated variants and gene expression levels. GTEx provides data on the relationship between the global RNA expression within multiple human tissues and variants genotypes. Variations in gene expression that are highly correlated with genetic variation can be identified as eQTLs. Because eQTLs are known to be tissue specific, we assessed the correlation between breast cancer associated variants and gene 
expression levels in breast mammary tissues from the GTEx database.

\section{Principle components analysis}

Minor allele frequencies of the selected SNPs in the different studied populations were used for principal components analysis (PCA) in order to study the different breast cancer genetic structures. Principal components analysis aims to synthesize information contained in a set of $n$ observed variables $\left(M_{1}, \ldots, M_{n}\right)$ by seeking a new set of $\mathrm{k}(\mathrm{k}<\mathrm{n})$ uncorrelated variables. The new variables, called principal components, are a linear combination of the observed variables. PCAs have been dressed with respect to the following criteria: percentage of missing genotypes, MAF $>0.05$, HWE $p$-value $>0.0001$ and $\mathrm{r}^{2}<0.6$. The resulting matrix was used for PCA calculation using the dudi.pca function from $\mathrm{R}$ packages. The plotting of the two first PCA were performed using the Factoextra R packages.

\section{Results}

In the present study, we investigated the breast cancer genetic architecture in a set of 135 subjects from the general Tunisian population by analyzing several previously identified breast cancer associated variations. Additional file 1: Table S1. summarizes the 90 breast cancer susceptibility loci that have been investigated in this current study. The studied genomic regions have been selected as follow: for the high and moderate penetrance genes we selected a genomic region that covers the LD block containing each gene in order to perform haplotype analysis. For low penetrance loci (SNPs) we studied a genomic region that covers $20 \mathrm{~kb}$ upstream and downstream of each SNP. We selected $20 \mathrm{~kb}$ on both sides in order to avoid overlap between variants that are located on the same locus. Thus, a $7 \mathrm{Mb}$ genomic region have been spanned for each of the 135 studied subjects.

One thousand five hundred eighty-seven variants directly genotyped on the array and located on these 90 selected loci have been included in this study. Among them, 28 SNPs are known to be associated with overall breast cancer risk (Table 1) including 3 SNPs already identified to be associated with breast cancer risk in the Tunisian population namely rs1219648, rs2981582 in FGFR2 and rs8051542 in TOX3 [46].

We therefore performed haplotype analysis by constructing LD blocks and phasing haplotypes on the 90 loci. We calculated correlation coefficients and allelic frequencies and characterized haplotype tagging SNPs (htSNPs). This constitutes a genetic database for use in further breast cancer association studies in the Tunisian population.

We determined the frequencies, in the Tunisian population, of at risk haplotype that carry at risk alleles of the
28 variants known to be associated with breast cancer risk (Fig. 1). Our results suggest that at risk haplotypes on 2p24, 4q21, 6q25, 9q31, 10q26,11p15, 11q13 and $14 \mathrm{q} 32$ loci are considerably frequent in the Tunisian population (haplotype frequency $>20 \%$ ), however, at risk haplotypes of the 2q31; 4q34, 7q35 and 22q13 loci seem to be rare (frequency $<5 \%$ ).

Moreover, we explored the functional role of the 28 selected variants. We performed analysis using RegulomeDB to identify DNA features and regulatory elements overlapping this set of variants and by applying a heuristic RegulomeDB score to prioritize candidate functional variants prior to further investigation (for a description of the RegulomeDB scoring scheme and referenced datatypes refer to http://www.regulomedb.org). High RegulomeDB scores were attributed to four SNPs: rs11099601, rs1494961, rs9911630 and rs4808801 (Table 1). Further functional annotations for each of these SNPs are shown in Additional file 1: Table S2.

The highly ranked score " $1 \mathrm{~b}$ " was assigned to the BRCA1-rs9911630 variant. The "1b" RegulomeDB score suggests that this variant is a putative functional SNP that may be associated to eQTL evidences. Then, eQTL associations have been assessed for the 28 variants using data from the GTEx database. In breast mammary tissues, significant eQTL associations have been observed for rs720475, rs3903072, rs9911630, rs799916 and rs4808801 (Table 1). The most strongly expression-associated variants were rs9911630 and rs799916, two strongly correlated variants in the $B R C A 1$ genomic region. Both variants were associated with expression levels of NBR2, CTD -3199 J23.6 and LINC00854 genes with a highly significant eQTL evidence for NBR2, a BRCA1 neighbor gene $(p=$ $1.2 \times 10^{-23}$ and $p=2.1 \times 10^{-25}$ for rs9911630 and rs799916, respectively) (Additional file 2: Figure S1).

Based on its interesting RegulomeDB score and the significant eQTL associations, we undertook further analysis for rs9911630. Using the Genevar platform, we assessed eQTL associations for rs9911630 in 8 populations. Data showed that rs9911630 is significantly associated with the expression level of BRCA1 gene (ILMN_173827-ENS G00000012048-BRCA1) in non-African populations (A sian (JPT and CHB) and Caucasian population (CEU)) but not in Africans. (Fig. 2a and b). Consequently, we compared the allelic frequencies of rs9911630 between these different populations.

Consistently with eQTL results, the frequency of rs9911630 is significantly different between Africans and non-African populations. Indeed, the "G" minor allele of rs9911630 in European and Asians shifted to a major allele in Africans (Additional file 1: Table S3). The allelic frequency of rs9911630 in Tunisia is significantly different from Africans and Asians and not different from Europeans and haplotype analysis using Haploview tagger 
Table 1 Distribution, minor allele frequencies and functional prediction of the selected breast cancer common variants

\begin{tabular}{|c|c|c|c|c|c|c|c|c|c|}
\hline Locus & Marker ID & Alleles & GMA & GMAF & $\begin{array}{l}\text { TUN } \\
\text { (freq) }\end{array}$ & Location & Score & $\begin{array}{l}\text { eQTL } \\
\text { associations }\end{array}$ & Predicted function \\
\hline $1 q 32.1$ & rs4245739 & $\mathrm{A} / \mathrm{C}$ & C & 0.2141 & 0,333 & Intergenic & 6 & $\begin{array}{l}\text { No } \\
\text { association }\end{array}$ & $\begin{array}{l}\text { 3UTR MDM4 miR-191 } \\
\text { target site and results in decreased MDM4 } \\
\text { expression }\end{array}$ \\
\hline $2 \mathrm{p} 24.1$ & rs12710696 & $\mathrm{T} / \mathrm{C}$ & $\mathrm{T}$ & 0.4455 & 51,1 & Intergenic & 4 & $\begin{array}{l}\text { No } \\
\text { association }\end{array}$ & $\begin{array}{l}\text { TF binding and DNase } \\
\text { peak }\end{array}$ \\
\hline $2 q 31.1$ & rs1550623 & $A / G$ & G & 0.1711 & 0,24 & Intergenic & 4 & $\begin{array}{l}\text { No } \\
\text { association }\end{array}$ & $\begin{array}{l}\text { TF binding and DNase } \\
\text { peak }\end{array}$ \\
\hline $4 q 21$ & rs1494961 & $\mathrm{C} / \mathrm{T}$ & C & 0.3355 & 52,6 & Exonic HELQ c.916G > A & if & $\begin{array}{l}\text { No } \\
\text { association }\end{array}$ & Tolerated \\
\hline $4 q 21$ & rs11099601 & $\mathrm{C} / \mathrm{T}$ & C & 0.33613 & 53,4 & 3 UTR FAM175A C.413 C>T & if & $\begin{array}{l}p=1.94 \times \\
10^{-21} \text { with } \\
\text { MRPS18C }\end{array}$ & $\begin{array}{l}\text { DAE eQTL and TF } \\
\text { binding / DNase peak }\end{array}$ \\
\hline $4 q 34.1$ & rs6828523 & $\mathrm{C} / \mathrm{A}$ & A & 0.2468 & 0,179 & $\begin{array}{l}\text { Intronic, ADAM29 c.-450- } \\
5711 C>A\end{array}$ & $\begin{array}{l}\text { No } \\
\text { data }\end{array}$ & $\begin{array}{l}\text { No } \\
\text { association }\end{array}$ & No data \\
\hline $6 \mathrm{p} 23$ & rs204247 & $A / G$ & G & 0.4321 & 0,37 & Intergenic (11 kb 5'-RANBP9) & 6 & $\begin{array}{l}\text { No } \\
\text { association }\end{array}$ & $\begin{array}{l}\text { Minimal functional } \\
\text { evidence }\end{array}$ \\
\hline $6 \mathrm{q} 25.1$ & rs2046210 & $\mathrm{G} / \mathrm{A}$ & A & 0.4121 & 0,45 & Intergenic, 6 kb 3'-CCDC170 & 6 & $\begin{array}{l}\text { No } \\
\text { association }\end{array}$ & $\begin{array}{l}\text { Minimal functional } \\
\text { evidence }\end{array}$ \\
\hline $7 q 35$ & rs720475 & $\mathrm{G} / \mathrm{A}$ & A & 0.1478 & 0,263 & $\begin{array}{l}\text { Intronic; ARHGEF5 C.4531+ } \\
646 \mathrm{G}>\mathrm{A}\end{array}$ & 5 & $\begin{array}{l}p=1.4 \times \\
10^{-6} \text { with } \\
\text { ARHGEF34P } \\
\text { gene and } \\
p=4.210^{-} \\
6 \text { for } \\
\text { OR2A9P } \\
\text { gene }\end{array}$ & $\begin{array}{l}\text { TF binding or DNase } \\
\text { peak }\end{array}$ \\
\hline $9 q 31.2$ & rs10759243 & $\mathrm{C} / \mathrm{A}$ & A & 0.4607 & 0,477 & Intergenic (53 kb 5'-KLF4) & $\begin{array}{l}\text { No } \\
\text { data }\end{array}$ & $\begin{array}{l}\text { No } \\
\text { association }\end{array}$ & No data \\
\hline 10p12.31 & rs7072776 & $\mathrm{G} / \mathrm{A}$ & A & 0.3055 & 0,441 & Intergenic (382 bp 3’ MLLT10) & 5 & $\begin{array}{l}\text { No } \\
\text { association }\end{array}$ & $\begin{array}{l}\text { TF binding or DNase } \\
\text { peak }\end{array}$ \\
\hline 10p15.1 & rs2380205 & $\mathrm{C} / \mathrm{T}$ & $\mathrm{T}$ & 0.3750 & 0,48 & Intergenic, 2.6 kb 5'-GD/2 & $3 a$ & $\begin{array}{l}\text { No } \\
\text { association }\end{array}$ & $\begin{array}{l}\text { TF binding, any motif } \\
\text { and DNase peak }\end{array}$ \\
\hline $10 q 22.3$ & rs704010 & $\mathrm{C} / \mathrm{T}$ & $\mathrm{T}$ & 0.2674 & 0,322 & $\begin{array}{l}\text { Intronic; ZMIZ1 c.-337+ } \\
12,121 \mathrm{~T}>\mathrm{C}\end{array}$ & $2 b$ & $\begin{array}{l}\text { No } \\
\text { association }\end{array}$ & $\begin{array}{l}\text { TF binding, any motif, } \\
\text { DNase Footprint and } \\
\text { DNase peak }\end{array}$ \\
\hline $10 q 26$ & rs1219648 & $A / G$ & G & 0.4089 & 0,466 & $\begin{array}{l}\text { Intronic; FGFR2 c.109+ } 7033 \\
T>C\end{array}$ & $\begin{array}{l}\text { No } \\
\text { data }\end{array}$ & $\begin{array}{l}\text { No } \\
\text { association }\end{array}$ & No data \\
\hline $10 q 26$ & rs2981582 & $\mathrm{G} / \mathrm{A}$ & A & 0.4038 & 0,463 & $\begin{array}{l}\text { Intronic, FGFR2 c.109+906 } \\
T>C\end{array}$ & 5 & $\begin{array}{l}\text { No } \\
\text { association }\end{array}$ & $\begin{array}{l}\text { TF binding or DNase } \\
\text { peak }\end{array}$ \\
\hline $11 q 13.1$ & rs3903072 & $\mathrm{G} / \mathrm{T}$ & $\mathrm{T}$ & 0.3165 & 0,467 & Intergenic (7.4 kb 3'-CFL 1) & 4 & $\begin{array}{l}p=9 \times 10^{-6} \\
\text { for } S N X 32, \\
\text { and } p= \\
2.9 \times 10^{-5} \\
\text { for CTSW }\end{array}$ & $\begin{array}{l}\text { TF binding and DNase } \\
\text { peak }\end{array}$ \\
\hline $11 \mathrm{p} 15.5$ & rs3817198 & $\mathrm{T} / \mathrm{C}$ & C & 0.2155 & 0,277 & 3 UTR LSP1 C. $13+200$ T >C & 5 & $\begin{array}{l}\text { No } \\
\text { association }\end{array}$ & $\begin{array}{l}\text { TF binding or DNase } \\
\text { peak }\end{array}$ \\
\hline $12 q 24.21$ & rs1292011 & $A / G$ & G & 0.4211 & 0,469 & Intergenic & 4 & $\begin{array}{l}\text { No } \\
\text { association }\end{array}$ & $\begin{array}{l}\text { TF binding and DNase } \\
\text { peak }\end{array}$ \\
\hline $14 q 24.1$ & rs2588809 & $\mathrm{C} / \mathrm{T}$ & $\mathrm{T}$ & 0.1831 & 0,298 & $\begin{array}{l}\text { Intronic RAD51B c.757-98,173 } \\
T>C\end{array}$ & $\begin{array}{l}\text { No } \\
\text { data }\end{array}$ & $\begin{array}{l}\text { No } \\
\text { association }\end{array}$ & No data \\
\hline $14 q 32.11$ & rs941764 & $A / G$ & G & 0.4193 & 0,468 & $\begin{array}{l}\text { Intronic CCDC88C c.271- } \\
15,014 \mathrm{~T}>\mathrm{C}\end{array}$ & 4 & $\begin{array}{l}\text { No } \\
\text { association }\end{array}$ & $\begin{array}{l}\text { TF binding and DNase } \\
\text { peak }\end{array}$ \\
\hline $16 q 12.1$ & rs3803662 & $\mathrm{G} / \mathrm{A}$ & A & 0.4403 & 0,414 & Intergenic, 5' to TOX3 & 5 & $\begin{array}{l}\text { No } \\
\text { association }\end{array}$ & $\begin{array}{l}\text { TF binding or DNase } \\
\text { peak }\end{array}$ \\
\hline $16 q 12.1$ & rs8051542 & $\mathrm{C} / \mathrm{T}$ & $\mathrm{T}$ & 0.3133 & 0,396 & $\begin{array}{l}\text { Intronic TOX3 C.88-3168 A > } \\
\text { G }\end{array}$ & 5 & $\begin{array}{l}\text { No } \\
\text { association }\end{array}$ & $\begin{array}{l}\text { TF binding or DNase } \\
\text { peak }\end{array}$ \\
\hline
\end{tabular}


Table 1 Distribution, minor allele frequencies and functional prediction of the selected breast cancer common variants (Continued)

\begin{tabular}{|c|c|c|c|c|c|c|c|c|c|}
\hline Locus & Marker ID & Alleles & GMA & GMAF & $\begin{array}{l}\text { TUN } \\
\text { (freq) }\end{array}$ & Location & Score & $\begin{array}{l}\text { eQTL } \\
\text { associations }\end{array}$ & Predicted function \\
\hline $16 \mathrm{q} 23.2$ & rs13329835 & $A / G$ & G & 0.2957 & 0,376 & $\begin{array}{l}\text { Intronic CDYL2 C.1007+ } 3855 \\
T>C\end{array}$ & 4 & $\begin{array}{l}\text { No } \\
\text { association }\end{array}$ & $\begin{array}{l}\text { TF binding and DNase } \\
\text { peak }\end{array}$ \\
\hline $17 q 21$ & rs9911630 & $A / G$ & G & 0.4972 & 0,426 & $\begin{array}{l}\text { 3'of BRCA1 } \\
\text { NC_000017.10:g.41188342A > } \\
\text { G }\end{array}$ & $1 b$ & $\begin{array}{l}p=1.2 \times \\
10^{-23} \text { for } \\
\text { NBR2 and } \\
p=1.3 \times \\
10^{-6} \text { for } \\
\text { CTD-3199 } \\
J 23.6 \text { and } p \\
=6.1 \times 10^{-6} \\
\text { for } \\
\text { LINC00854 }\end{array}$ & $\begin{array}{l}\text { eQTL, TF binding, any } \\
\text { motif, DNase Footprint } \\
\text { and DNase peak }\end{array}$ \\
\hline $17 q 21$ & rs799916 & $\mathrm{T} / \mathrm{G}$ & $\mathrm{T}$ & 0.4976 & 0,404 & $\begin{array}{l}\text { Intronic BRCA1 c.4097-141A > } \\
\text { C }\end{array}$ & 6 & $\begin{array}{l}p=2.1 \times \\
10^{-25} \text { for } \\
\text { NBR2 } p= \\
8.3 \times 10^{-7} \\
\text { for CTD- } \\
3199 \mathrm{~J} 23.6 \\
\text { and } p \\
=3.7 \times \\
10^{-6} \text { for } \\
\text { LINC00854 }\end{array}$ & Minimal functional evidence \\
\hline $18 q 11.2$ & rs1436904 & $\mathrm{T} / \mathrm{G}$ & G & 0.3568 & 0,292 & $\begin{array}{l}\text { Intronic CHST9 C.202 + } \\
33413 \mathrm{~A}>\mathrm{C}\end{array}$ & $\begin{array}{l}\text { No } \\
\text { data }\end{array}$ & $\begin{array}{l}\text { No } \\
\text { association }\end{array}$ & No data \\
\hline 19p13.11 & rs4808801 & $A / G$ & G & 0.4521 & 0,404 & $\begin{array}{l}\text { Intronic ELL c.744 + 1247T> } \\
\text { C }\end{array}$ & if & $\begin{array}{l}p=1.6 \times \\
10^{-5} \text { for } \\
\text { SSBP4 }\end{array}$ & eQTL, TF binding and/or DNase peak \\
\hline $22 q 13.1$ & rs6001930 & $\mathrm{T} / \mathrm{C}$ & C & 0.1414 & 0,109 & $\begin{array}{l}\text { Intronic MKL1 C.-59-16944A > } \\
\text { G }\end{array}$ & 5 & $\begin{array}{l}\text { No } \\
\text { association }\end{array}$ & TF binding or DNase peak \\
\hline
\end{tabular}

-GMA Global Minor Allele, GMAF Global Minor Allele Frequency, TUN (freq) the frequency of the global minor allele in the Tunisian population, Score: from the RegulomeDB database and score significance provided in the predicted function column, eQTL association provided by the GTEx database, $p$ the $p$ value of the variants' eQTL association, TF Transcription factor

-The highlighted rows indicate polymorphisms that showed the highest RegulomeDB scores, significant eQTL associations and other functional evidence -rs1494961 is the only exonic variant in this list, we provided its predicted functional significance using the Sift software

-In bold, SNPs previously identified as associated with breast cancer risk in the Tunisian population

tool showed that rs9911630 is a haplotype tagging SNP in the Tunisian population (Fig. 2c).

In silico predictions of micro RNA binding sites of rs9911630, as a BRCA1-3' variant, have been also performed using mirBase. In silico analysis predicts that rs9911630 alters the binding sites of three non human microRNAs by the gain of mse-miR-2766 binding site and the loss of bmo-miR3287 and ssa-miR-19d-5p binding sites (Additional file 2: Figure S2; Additional file 1: Table S4).

Based on the different allelic frequencies of rs9911630 $(A>G)$ in the different ethnic groups investigated in this study, we suggested that the effect of rs9911630 on the microRNAs binding sites will differ from one population to another. Indeed, in European and Asian populations, rs9911630 would cause a gain of miR-2766 binding and a loss of bmo-miR3287 and ssa-miR-19d-5p Micro-RNAs. However, in Africans, rs9911630 would act in a different way by promoting the binding of bmo-miR3287 and ssa-miR-19d-5p and loosing the binding site of miR-2766.

Finally, we used the chi-square statistical test to compare the genetic characteristics of the selected 28 SNPs between TUN and other populations (Additional file 1: Table S3). Interestingly, the frequency of rs13329835 seems to differ significantly between the Tunisian population and all other HapMap populations. In addition, three SNPs (rs2046210, rs941764 and rs3803662) showed significant difference in their frequencies between Tunisian and European (CEU + TSI), Asian (CHB + JPT) and African populations (MKK, LWK and YRI). However, no significant differences have been observed between rs3803662 frequencies in Tunisian and in ASW and MEX populations that are considered as admixed populations. For the remaining 24 SNPs, significant differences either with Africans, Europeans or Asians were observed. In addition, in order to investigate the breast cancer genetic architecture in different ethnic groups, we studied the distribution of the studied population using a principle component analysis based on the frequencies of the 28 genotyped variants. PCA revealed clear distinction of the breast cancer architecture among the three human geographic origins (Europe, Asia and Africa) (Fig. 3). Admixed populations such as MEX and 


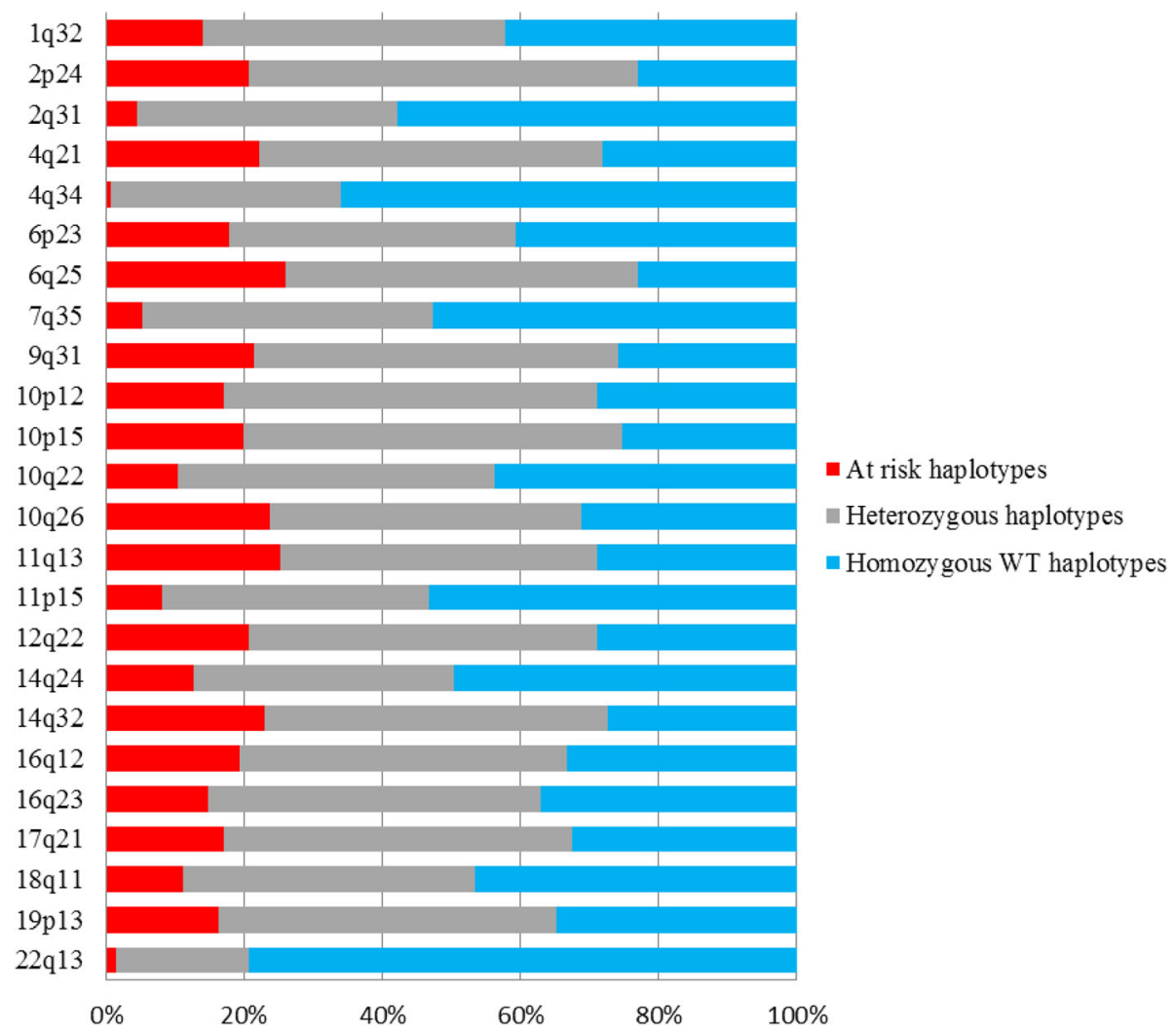

Fig. 1 Distribution of breast cancer at risk haplotypes in the general Tunisian population. After phasing the identified haplotypes in the Tunisian population, the frequencies of at risk haplotypes (in red; identified as haplotypes carrying at risk alleles, those that have been identified as associated with the disease and usually considered as the minor alleles) have been calculated. At risk haplotypes with frequency $\geq 5 \%$ are considered as relatively common haplotypes

GIH seem to cluster in an intermediate position. However, TUN population seems to cluster close to Europeans populations.

Moreover, the first principal component (Fig. 3a) sho wed that the largest inter-ethnic variability is found between African and non-African populations (49.5\%). A set of 15 variants that contributed significantly to the observed genetic variability between African and non -African populations (Dim1) have been characterized (Additional file 2: Figure S3a). rs4808801 seems to be the variant that contributed more to this inter-ethnic variability. rs9911630 also figure in the list of variants that contribute very significantly to the genetic variability between African and non-African populations. PCA results also showed that the variability between European populations (CEU and TSI) and non-European ones, is about $27.8 \%$ and a list of 11 variants have been also identified as the most contributors to the genetic variability between these populations (Dim2) (Additional file 2: Figure $\mathrm{S} 3 \mathrm{~B}$ ).

Consistently with the PCA results, we also showed that YRI, LWK and JPT populations are the most contributors to variability between African and non-Africans (Dim 1), and TUN, MEX and GIH are those who contributed less to this variability (Additional file 2: Figure S4A). This represents an additional argument toward the admixed and intermediate classification of these populations.

However, the Tunisian population altogether with the TSI and CHB populations are the most contributors to diversity between Europeans and non-Europeans, which confirms the close genetic relationship between Tunisians and population from European ancestry (Additional file 2: Figure S4B).

In order to explore the genetic relationship between North African and European populations, we performed another PCA using a new matrix that integrates values from additional populations from North Africa (Tunisian Berbers, Moroccans and Egyptians) and Southern Europe mainly from Spain. This second analysis confirmed the close genetic relationship between North African populations and Europeans (Fig. 3b).

\section{Discussion}

Several differences have been observed in breast cancer epidemiological features between populations [57]. This is mainly due to different demographic, environmental 


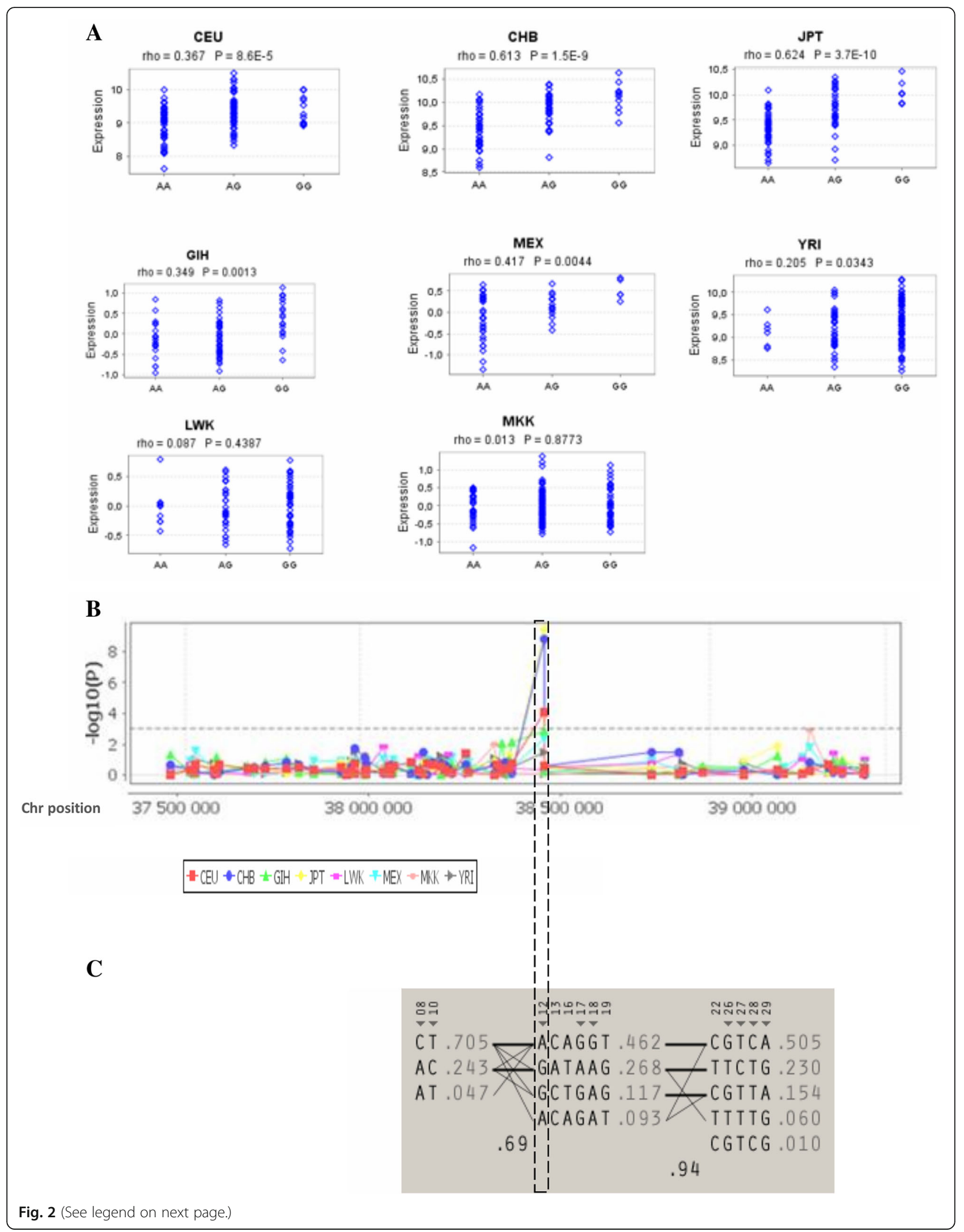


(See figure on previous page.)

Fig. 2 eQTL analysis of the rs9911630- BRCA1 variant in different populations. a rs9911630 was tested for correlation with BRCA1 gene expression using the eQTL database GENe Expression VARiation (Genevar) from Sanger institute plateform. eQTLs in 8 different HapMap populations are showed in this figure (CEU: Utah residents with Northern and Western European ancestry from the CEPH, CHB: Han Chinese in Beijing, China; JPT: Japanese in Tokyo, Japan; GIH: Gujarati Indians in Houston, MEX: Mexican ancestry in Los Angeles, California; YRI: Yoruba in Ibadan, Nigeria; LWK: Luhya in Webuye, Kenya; MKK: Maasai in Kinyawa, Kenya). The 8 Box plots represent BRCA1 expression levels on the $y$ axis with respect to the rs9911630 genotypes showed on the $x$ axis. $P$ values $(P)<0.05$ means significant eQTL associations. $\mathbf{b}$ eQTL association results across different HapMap populations are shown on the $y$ axis (log10). The chromosomal position of the BRCA1 gene (chr17:38449840-38,530,994 according to NCBI36/hg18 assembly) is shown on the $x$ axis. eQTL peaks represent the significant eQTL correlation that have been observed for rs 9911630 in Caucasian, Chinese and Japanese samples. c Haplotype blocks constructed with variants identified in the Tunisian subjects showing a frequency $\geq 5 \%$. Tagging SNPs identified on a block-by-block basis are denoted with an arrow below the SNP number. Tunisian haplotype frequencies are displayed on the right of each haplotype combination, while the level of recombination is displayed below the connections between the blocks. Thick connections represent haplotypes with frequencies $\geq 5 \%$, while frequencies below $5 \%$ are represented by thin lines. Variant \#12 is rs9911630

and lifestyle factors, but also result from differences in genetic architecture from one population to another. Indeed, it has been shown that American women from African origins (Afro-Americans) are three times more likely than Caucasian Americans to develop the highly aggressive triple-negative and inflammatory breast cancer forms [58]. Moreover, several studies showed that high rate and long history of consanguinity, commonly observed in developing countries, decrease breast cancer incidence rate by decreasing the frequency of mutations in high penetrant breast cancer genes such as BRCA1 and $B R C A 2[59,60]$. In Tunisia, mutation prevalence of these two genes is considered lower than in Europe with 19.7 and $7.5 \%$ for $B R C A 1$ and BRCA2 respectively [61]. Medimegh et al. [62] suggested that in the absence of deleterious mutations on BRCA1, wild type alleles of $B R C A 1$ genetic variants seem to decrease the expression level of the BRCA1 in 50\% of familial breast cancer cases through their interaction with micro-RNAs (miRNAs) that are increasingly recognized as mediators in a variety of biological processes including breast cancer [62].

Because of the lack of large studies on common breast cancer genetic variation in the Tunisian population, we undertook this genome wide study with a focus on 90 breast cancer loci. We investigated differences and similarities between these loci in terms of allelic frequencies in more than 11 different populations, we also investigated linkage disequilibrium, correlation ratios and haplotype structure of breast cancer loci in Tunisia. Moreover, in silico functional assessment of the most relevant SNPs have been performed. This study represent the largest and the most complete study on common breast cancer variants in the Tunisian and North African populations.

Genome wide-PCA performed in this current study (data not shown) showed the admixed and intermediate genetic architecture of the Tunisian population. Although it's geographic belonging to the African continent, the Tunisian genetic characteristics of breast cancer common variants seems to be closer to Europeans than to Africans.
The close genetic relationship between Tunisian population and Europeans may be explained by migratory waves that happened in the Mediterranean region since the Paleolithic period. Different studies using mitochondrial DNA, Y chromosome and SNP genotyping in Tunisia also showed the admixed and intermediate genetic architecture of the Tunisian population [63-67].

Haplotype analysis of the selected breast cancer susceptibility loci, showed that at risk haplotypes on $2 \mathrm{p} 24,4 \mathrm{q} 21$, 6q25, 9q31, 10q26,11p15, 11q13 and 14q32 loci are considerably frequent in the Tunisian population $(>20 \%)$. When comparing the allele frequencies of several common variants between Tunisian and other ethnic groups, some variants found on these loci showed significant differences between populations. Indeed, 6q25-rs2046210 and 14q32-rs941764, differ significantly between Tunisians and all other population expect ASW and MEX populations, respectively. This represents an argument of the admixed nature of the Tunisian population.

The 6q25 represents an ambiguous locus in breast cancer association studies in different ethnic groups [21]. Indeed, rs2046210 was found to be associated with breast cancer risk in European and East Asian populations but not in African populations. However, subsequent studies showed that other variants on the 6q25 region are associated with breast cancer risk in Africans namely: rs9397435 and rs2046211 [68]. Interestingly, the 6q25 locus contains the ESR1 gene that encodes for the estrogen receptor protein which is strongly involved in breast carcinogenesis. Thus, association studies of the 6q25 SNPs in the North African population may help to explain the development of specific breast cancer phenotypes in North African population such as the triple negative breast cancer subtype.

Moreover, two variants (rs1219648 and rs2981582) found on the 10q26 locus have been recently identified as associated with breast cancer risk in the Tunisian population [54]. These two variants seem to be in a strong correlation $\left(\mathrm{r}^{2}=0.8\right.$, Additional file 2: Figure S5.) meaning that they are carried by the same haplotype. 
A

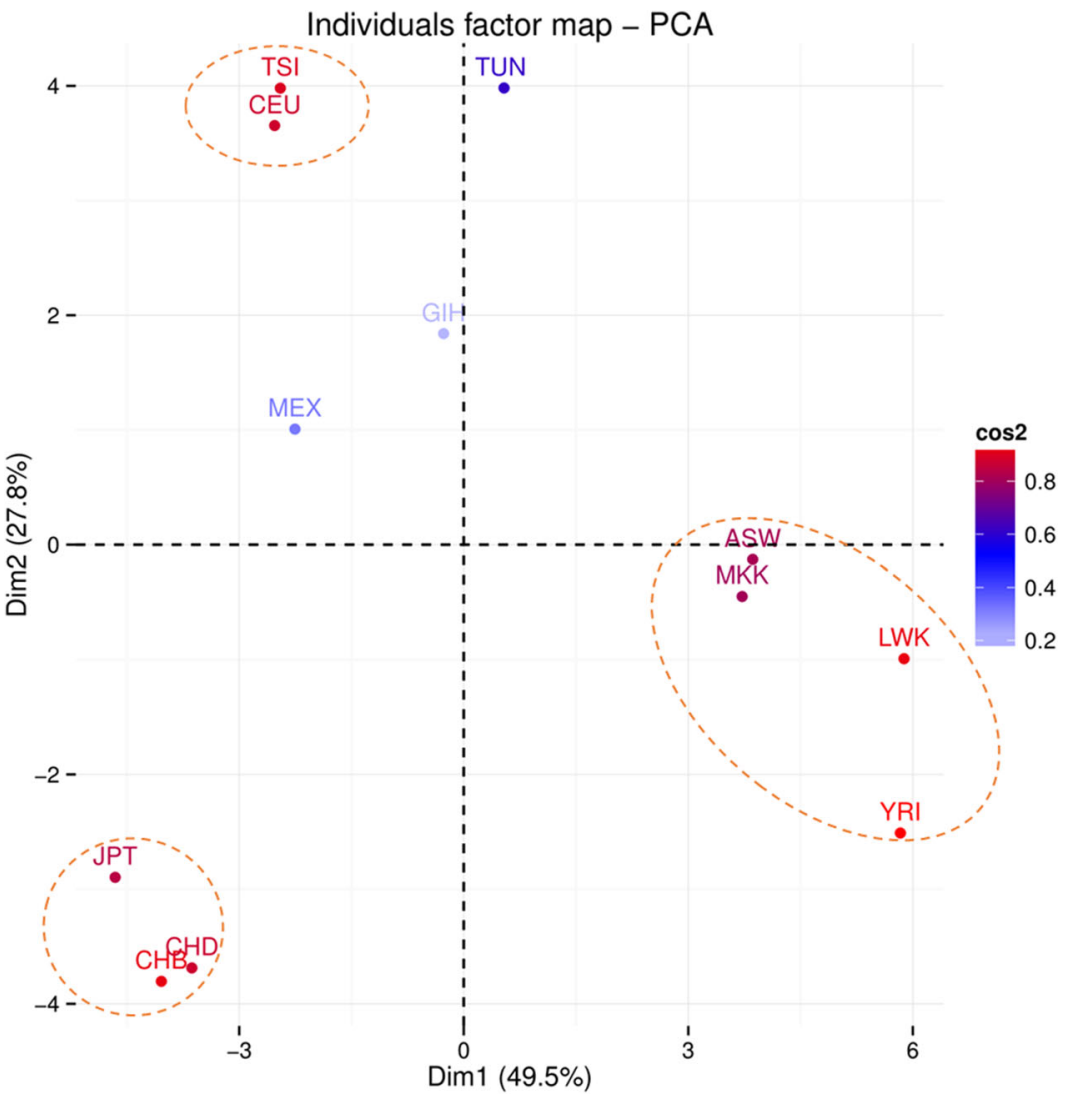

B

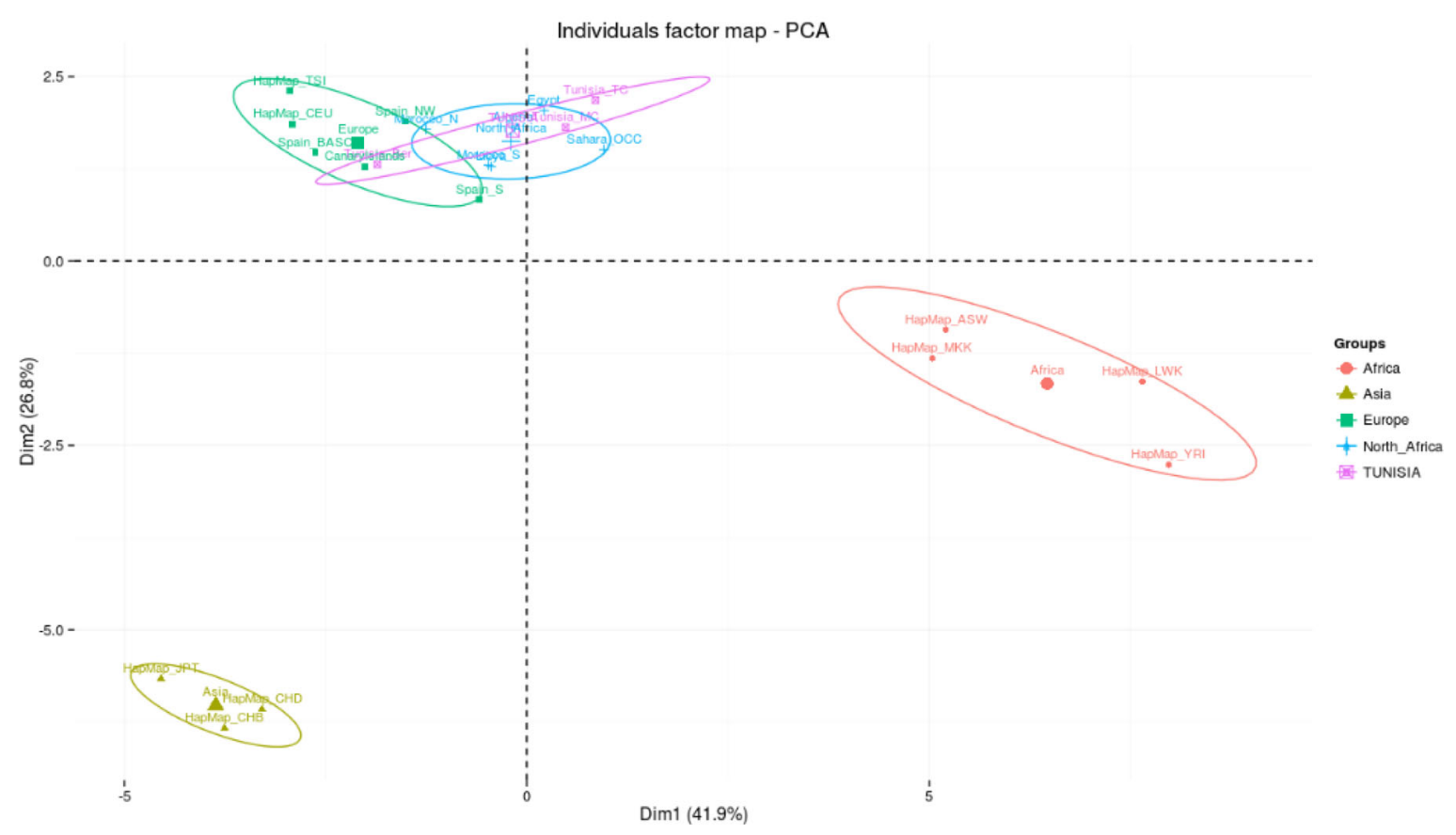

Fig. 3 Principle component analysis showing population distribution based on the MAF of the 28 selected variants. a Tunisian and HapMap populations. b Other sub-populations from North Africa and other ethnic groups 
Therefore, further analysis on the 10q26 locus in the TUN population should be prioritized.

In addition, the frequency of rs13329835 seems to differ significantly between Tunisians and all other HapMap populations. Recent studies showed that this variant is associated with breast cancer risk in Europeans and Afro Americans $[24,69]$. Because, the allele frequency for this SNP differ considerably across ethnic groups, association studies in the Tunisian population are required to assess its association with breast cancer risk.

We also performed in silico functional analysis in order to identify SNPs more or less likely to have functional effects. High RegulomeDB scores were assigned to variants on the 4q21, 19p13 and 17q21 loci.

The functional impact of rs1494961 and rs11099601 at $4 \mathrm{q} 21$ locus have been previously investigated by our group using eQTL analysis and ENCODE data. Significant eQTL associations and interactions with different biofeatures such as histones and enhancer elements have been identified for these two SNPs [70].

Fine-scale mapping studies have been also performed on the 19p13 locus in order to identify causal variants at this breast cancer susceptibility locus [71]. In this current study, 19p13-rs4808801 was identified as a putative functional SNP with interesting functional evidence (eQtl association with SSBP4 gene, $p=1.6 \times 10^{-5}$ ). Our data also showed that rs4808801 is the variant that contributed more to the inter-ethnic genetic diversity between African and non-African-populations.

However, no functional studies have been reported for 17q21-rs9911630 except one of our previous studies that mentioned the potential association of this variant with differential allelic expression [62].

Here, we identified rs9911630-BRCA1 variant as a haplogroup tagging SNP in the Tunisian population. Statistical analysis also showed that the frequency of this variant varies significantly between ancient populations (Africans) and more recent ones (Europeans and Asians). rs9911630 frequency in Tunisia seems to be between that of Europeans and Africans which would be expected in this admixed population with European and African heritage. eQTL analysis indicated that rs9911630 is significantly associated with the expression levels of NBR2 and $B R C A 1$ genes. Significant eQTls were also observed between rs9911630 and other genes namely: CTD-3199 J23.6 and LINC00854.

The observed eQTLs associated between rs9911630 and BRCA1 derived from analysis performed in fibroblast, lymphoblastoid cell line and T cell. However, eQTL associations between this variant and NBR2, CTD-3199 J23.6 and LINC00854 derived from breast mammary cell lines. As regulatory effects are often tissue-specific this may explain the different eQTL associations observed in these different cell types. CTD-3199J23.6 is a transcribed processed pseudogene, no further information on it is function or its involvement in carcinogenesis have been reported. LINC00854 is an RNA gene, and is affiliated with long non-coding RNA class (lncRNAs). NBR2 is also a non-protein coding gene that encodes a long non-coding RNA and suppresses tumor development through regulation of adenosine monophosphate-activated protein kinase (AMPK) activation [72]. It resides adjacent to the tumor suppressor gene $B R C A 1$. Given the close proximity of the human BRCA1 and NBR2 genes, it has been suggested that these 2 genes may be coordinately expressed. Since many lncRNAs regulate the transcription of neighboring genes, the hypothesis that NBR2 regulates BRCA1 transcription is also plausible [73].

lncRNAs is still a poorly understood class of non-coding RNAs that refer to a classified group of RNA transcripts longer than 200 nucleotides and have no apparent protein-coding potential. Accumulating recent evidence links long non-coding RNAs to cancer metabolism by regulating various aspects of cancer metabolism through their cross-talk with other macromolecules [74, 75]. In addition, recent studies showed that lncRNAs can cross -talk with other non-coding RNAs such as microRNAs through competing endogenous RNA (ceRNA) mechanisms [76]. Interestingly, our results indicated that rs9911630 alters the binding sites of three non-human miRNAs (miR-2766, bmo-miR3287 and ssa-miR-19d-5p). The regulation of gene expression by cross-species microRNAs has been previously reported and their link to cancer development or prevention have been also explored [77]. Indeed, non-human microRNA such as plant and animal derived microRNAs have been detected in human blood in a large nutrigenomics study cohort [77]. Moreover, the role of food-related microRNAs in regulating the expression of key human cancer-related genes was highly debated $[78,79]$. Thus, long and small non coding RNAs (lncRNAs and microRNAs), altogether with protein-coding RNAs may form complex regulatory networks involved in various aspects of cancer biology.

Interestingly, significant eQTL associations observed between rs9911630 and BRCA1 have been observed only in European and Asian individuals but not in Africans and the allele frequencies of this variants also differ significantly between African and non-African populations. We hypothesized that differences in $B R C A 1$ expression levels between African and non African populations may be explained by difference in the allele frequency of this variants and by differences in the expression level of some exogenous microRNAs mainly due to different environmental and lifestyle factors such as food intake habits. Moreover, in a separate study, we identified rs16942-BRCA1 as a modifier variant of breast cancer risk in BRCA1 mutation carriers [80]. rs16942 seems to be in complete LD with rs9911630 in populations from 
European origins but not in African populations. Thus, we suggest that rs9911630 is a potential functional variant that may be associated with breast cancer risk in an ethnic specific manner by altering the expression level of key tumor suppressor genes such as BRCA1 and NBR2. However, the association of this variant with breast cancer risk in different ethnic groups warrants further association and functional investigations.

\section{Conclusions}

The goal of this research was to explore the genetic architecture of a number of breast cancer risk SNPs in the Tunisian population comparing their frequency to 11 different ethnic groups. The observed discordance in the genetic background between populations highlights the necessity for researchers to establish a specific genotype profile for each population. Therefore, caution should be exercised in applying any genetic risk prediction model based on tagSNPs outside of the ancestry group in which it was derived. To our best knowledge, this study is the largest investigation of breast cancer common loci in the general Tunisian population. Further investigations are in progress by our group regarding the association of the potential functional variants identified in this study and breast cancer risk in the Tunisian population.

\section{Additional files}

Additional file 1: Table S1 Breast cancer loci and variants investigated in the Tunisian population. Table S2 Data sources for in silico analyses of variants with high RegulomeDB scores. Table S3 Allelic frequency of the selected breast cancer polymorphisms and comparison of these

frequencies between Tunisian and HapMap populations (Pairwise pvalues $<0.05$ ). *Polymorphisms highlighted in grey are the four SNPs that

showed an allelic frequency significantly different between Tunisians and all other HapMap populations. Table S4 MicroRNA binding sites altered by the BRCA1-rs9911630 variant. (DOCX $410 \mathrm{~kb}$ )

Additional file 2: Figure S1 GTEX Boxplots representing the most significant eQTL results for variant rs9911630 in breast mammary tissue. Box plots represent the expression levels of the indicated transcripts with respect to the rs9911630 genotypes. Expression levels are shown for (a) NBR2 gene, (b) CTD-3199 J23.6 gene and (c) LINC00910 gene. Horizontal bars indicate mean expression level per genotype. Additional information on the eQTL $p$ values are reported in Table 1. Figure S2 Alignment of the sequence around rs9911630 with binding site of (a) bmo-miR-3287, (b) ssa-miR-19d-5p and (c) mse-miR-2766. The SNP is shown in red and the allele binding the microRNA is also shown. Figure S3 Contributions of variables (SNPs and populations) in Dim1 and Dim2. The contribution of each tested variable (based on their variants frequencies) in the general variability between the different selected populations shown on the PCA (a) to the first dimension of the PCA (Dim1 for the variability between African and non-African populations -see Fig. 3) and (b) to the second dimension of the PCA (Dim2 for the variability between European and non-European populations). Figure $\mathbf{S} \mathbf{4}$ Contributions of each tested population in the general variability between the different selected populations shown on the PCA (a) the first dimension of the PCA (Dim1) and (b) the second dimension of the PCA (Dim2). Figure S5 A map of the linkage disequilibrium in intron 2 of FGFR2 gene containing two SNPs associated with breast cancer risk in the Tunisian population (rs1219648 and rs2981582). (DOCX $263 \mathrm{~kb})$

\section{Abbreviations}

ASW: African ancestry in Southwest USA; BC: Breast Cancer; CEU: Utah residents with Northern and Western European ancestry from the CEPH collection; CHB: Han Chinese in Beijing, China; CHD: Chinese in Metropolitan Denver, Colorado; ENCODE: ENCyclopedia Of DNA elements; Genevar: GENe Expression VARiation; GIH: Gujarati Indians in Houston, Texas; GMAF: Global Minor Allele Frequency; Haplogroup: Haplotype groups; htSNPs: Haplotype tag SNPs; HW: Hardy Weinberg; HWE: Hardy-weinberg equilibrium; IBS: Identity-by-state; JPT: Japanese in Tokyo, Japan; LD: Linkage disequilibrium; LWK: Luhya in Webuye, Kenya; MAF: Minor allele frequency; MDS: MultiDimensional scaling; MENA: North African and Middle East; MEX: Mexican ancestry in Los Angeles, California; MKK: Maasai in Kinyawa, Kenya; PCA: Principal components analysis; SNP: Single nucleotide polymorphism; TSI: Toscans in Italy; TUN: Tunisian population; YRI: Yoruba in Ibadan, Nigeria

\section{Acknowledgements}

The authors would like to thank all the individuals who took part in this study and all the researchers, clinicians, technicians and administrative staff who have enabled this work to be carried out.

\section{Funding}

This work was supported by the "Qatar National Research Foundation" (NPRP 08-083-3-031) that contributed to the design of the study, collection, analysis, interpretation of data and in writing the manuscript.

\section{Availability of data and materials}

The datasets used and/or analyzed during the current study are available from the corresponding author on reasonable request.

\section{Authors' contributions}

YH: Performed data analysis and drafted the article. MBR: Participated in patients' recruitment and in the data analysis. JS: Participated in the molecular analysis. MN: Participated in the statistical analysis. OM: Participated in patients' recruitment and revised the manuscript. ABE: Helped in manuscript revision. RM: Helped in manuscript revision. LC: Coordinated the study and helped in manuscript revision. MSB: Coordinated the study. SA: Coordinated the study and helped with the draft of the manuscript. HB: Coordinated the study and revised the manuscript. LR: Participated in the data extraction and analysis and revised the manuscript. All authors read and approved the final manuscript.

\section{Ethics approval and consent to participate}

The present study was approved by the institutional review board of Pasteur Institute of Tunis; registration number (IRB00005445, WA00010074). All patients gave their written informed consent.

\section{Consent for publication}

Not applicable.

\section{Competing interests}

The authors declare that they have no competing interests.

\section{Publisher's Note}

Springer Nature remains neutral with regard to jurisdictional claims in published maps and institutional affiliations.

\section{Author details}

'Laboratory of biomedical genomics and oncogenetics, Institut Pasteur de Tunis, Université Tunis El Manar, 13, Place Pasteur BP 74, 1002 Tunis, Belvédère, Tunisie. ${ }^{2}$ Department of Genetic Medicine, Weill Cornell Medical College-Qatar, Doha, Qatar. ${ }^{3}$ Laboratory of Genetics, Immunology and Human Pathology, Department of Biology, Faculty of Sciences of Tunis, University of Tunis El Manar, Tunis, Tunisia. ${ }^{4}$ Department of Human Genetics, Charles Nicolle Hospital, Tunis, Tunisia. ${ }^{5}$ Medical Oncology Department, Abderrahmen Mami Hospital, Ariana, Tunisia. ${ }^{6}$ Department of Biology, Faculty of Science of Bizerte, Université Tunis Carthage, Tunis, Tunisia. 
Received: 30 January 2018 Accepted: 26 November 2018 Published online: 29 December 2018

\section{References}

1. Sinha R, Coyle C, Ring A. Breast cancer in older patients: national cancer registry data. Int J Clin Pract. 2013;67(7):698-700.

2. Ghoussaini M, Pharoah PD, Easton DF. Inherited genetic susceptibility to breast cancer: the beginning of the end or the end of the beginning? Am J Pathol. 2013;183(4):1038-51.

3. Feunteun J, Lenoir GM. BRCA1, a gene involved in inherited predisposition to breast and ovarian cancer. Biochim Biophys Acta. 1996;1242(3):177-80.

4. Miki Y, Swensen J, Shattuck-Eidens D, Futreal PA, Harshman K, Tavtigian S, Liu Q, Cochran C, Bennett LM, Ding W, et al. A strong candidate for the breast and ovarian cancer susceptibility gene BRCA1. Science (New York, NY). 1994;266(5182):66-71.

5. Tavtigian SV, Simard J, Rommens J, Couch F, Shattuck-Eidens D, Neuhausen S, Merajver S, Thorlacius S, Offit K, Stoppa-Lyonnet D, et al. The complete BRCA2 gene and mutations in chromosome 13q-linked kindreds. Nat Genet. 1996;12(3):333-7.

6. Wooster R, Bignell G, Lancaster J, Swift S, Seal S, Mangion J, Collins N, Gregory S, Gumbs C, Micklem G. Identification of the breast cancer susceptibility gene BRCA2. Nature. 1995;378(6559):789-92.

7. Borresen AL, Andersen TI, Garber J, Barbier-Piraux N, Thorlacius S, Eyfjord J, Ottestad L, Smith-Sorensen B, Hovig E, Malkin D, et al. Screening for germ line TP53 mutations in breast cancer patients. Cancer Res. 1992;52(11):3234-6.

8. Venkateshwari A, Clark DW, Nallari P, Vinod C, Kumarasamy T, Reddy G, Jyothy A, Kumar MV, Ramaiyer R, Palle K. BRIP1/FANCJ mutation analysis in a family with history of male and female breast Cancer in India. J Breast Cancer. 2017;20(1):104-7.

9. Lin PH, Kuo WH, Huang AC, Lu YS, Lin CH, Kuo SH, Wang MY, Liu CY, Cheng $\mathrm{FT}$, Yeh $\mathrm{MH}$, et al. Multiple gene sequencing for risk assessment in patients with early-onset or familial breast cancer. Oncotarget. 2016;7(7):8310-20.

10. Ren LP, Xian YS, Diao DM, Chen Y, Guo Q, Dang CX. Further evidence for the contribution of the BRCA1-interacting protein-terminal helicase 1 (BRIP1) gene in breast cancer susceptibility. Genet Mol Res. 2013;12(4):5793-801.

11. Meijers-Heijboer $H$, Wijnen J, Vasen $H$, Wasielewski M, Wagner A, Hollestelle A, Elstrodt F, van den Bos R, de Snoo A, Fat GT, et al. The CHEK2 1100delC mutation identifies families with a hereditary breast and colorectal cancer phenotype. Am J Hum Genet. 2003;72(5):1308-14.

12. Le Calvez-Kelm F, Lesueur F, Damiola F, Vallee M, Voegele C, Babikyan D, Durand G, Forey N, McKay-Chopin S, Robinot N, et al. Rare, evolutionarily unlikely missense substitutions in CHEK2 contribute to breast cancer susceptibility: results from a breast cancer family registry case-control mutation-screening study. Breast Cancer Res. 2011;13(1):R6.

13. Renwick A, Thompson D, Seal S, Kelly P, Chagtai T, Ahmed M, North B, Jayatilake $H$, Barfoot $R$, Spanova $K$, et al. ATM mutations that cause ataxia-telangiectasia are breast cancer susceptibility alleles. Nat Genet. 2006;38(8):873-5.

14. Tavtigian SV, Oefner PJ, Babikyan D, Hartmann A, Healey S, Le Calvez-Kelm F, Lesueur F, Byrnes GB, Chuang SC, Forey N, et al. Rare, evolutionarily unlikely missense substitutions in ATM confer increased risk of breast cancer. Am J Hum Genet. 2009;85(4):427-46.

15. Erkko H, Xia B, Nikkila J, Schleutker J, Syrjakoski K, Mannermaa A, Kallioniemi A, Pylkas K, Karppinen SM, Rapakko K, et al. A recurrent mutation in PALB2 in Finnish cancer families. Nature. 2007:446(7133):316-9.

16. Cox A, Dunning AM, Garcia-Closas M, Balasubramanian S, Reed MW, Pooley KA, Scollen S, Baynes C, Ponder BA, Chanock S, et al. A common coding variant in CASP8 is associated with breast cancer risk. Nat Genet. 2007;39(3):352-8.

17. Easton DF, Pooley KA, Dunning AM, Pharoah PD, Thompson D, Ballinger DG, Struewing JP, Morrison J, Field H, Luben R, et al. Genome-wide association study identifies novel breast cancer susceptibility loci. Nature. 2007; 447(7148):1087-93.

18. Hunter DJ, Kraft P, Jacobs KB, Cox DG, Yeager M, Hankinson SE, Wacholder S, Wang Z, Welch R, Hutchinson A, et al. A genome-wide association study identifies alleles in FGFR2 associated with risk of sporadic postmenopausal breast cancer. Nat Genet. 2007;39(7):870-4.

19. Stacey SN, Manolescu A, Sulem P, Thorlacius S, Gudjonsson SA, Jonsson GF, Jakobsdottir M, Bergthorsson JT, Gudmundsson J, Aben KK, et al. Common variants on chromosome $5 \mathrm{p} 12$ confer susceptibility to estrogen receptorpositive breast cancer. Nat Genet. 2008;40(6):703-6.
20. Ahmed S, Thomas G, Ghoussaini M, Healey CS, Humphreys MK, Platte R, Morrison J, Maranian M, Pooley KA, Luben R, et al. Newly discovered breast cancer susceptibility loci on 3p24 and 17q23.2. Nat Genet. 2009;41(5):585-90.

21. Zheng W, Long J, Gao YT, Li C, Zheng Y, Xiang YB, Wen W, Levy S, Deming $S L$, Haines $J L$, et al. Genome-wide association study identifies a new breast cancer susceptibility locus at 6q25.1. Nat Genet. 2009;41(3):324-8.

22. Thomas G, Jacobs KB, Kraft P, Yeager M, Wacholder S, Cox DG, Hankinson SE, Hutchinson A, Wang Z, Yu K, et al. A multistage genome-wide association study in breast cancer identifies two new risk alleles at 1 p11.2 and 14q24.1 (RAD51L1). Nat Genet. 2009;41(5):579-84.

23. Stacey SN, Manolescu A, Sulem P, Rafnar T, Gudmundsson J, Gudjonsson SA, Masson G, Jakobsdottir M, Thorlacius S, Helgason A, et al. Common variants on chromosomes $2 \mathrm{q} 35$ and $16 \mathrm{q} 12$ confer susceptibility to estrogen receptor-positive breast cancer. Nat Genet. 2007;39(7):865-9.

24. Michailidou K, Hall P, Gonzalez-Neira A, Ghoussaini M, Dennis J, Milne RL, Schmidt MK, Chang-Claude J, Bojesen SE, Bolla MK, et al. Large-scale genotyping identifies 41 new loci associated with breast cancer risk. Nat Genet. 2013;45(4):353-61 361e351-352.

25. Garcia-Closas M, Couch FJ, Lindstrom S, Michailidou K, Schmidt MK, Brook MN, Orr N, Rhie SK, Riboli E, Feigelson HS, et al. Genome-wide association studies identify four ER negative-specific breast cancer risk loci. Nat Genet. 2013;45(4):392-8 398e391-392.

26. Bojesen SE, Pooley KA, Johnatty SE, Beesley J, Michailidou K, Tyrer JP, Edwards SL, Pickett HA, Shen HC, Smart CE, et al. Multiple independent variants at the TERT locus are associated with telomere length and risks of breast and ovarian cancer. Nat Genet. 2013:45(4):371-84 384e371-372.

27. Corbex M, Bouzbid S, Boffetta P. Features of breast cancer in developing countries, examples from North-Africa. Eur J Cancer (Oxford, England: 1990). 2014;50(10):1808-18.

28. Bray F, McCarron P, Parkin DM. The changing global patterns of female breast cancer incidence and mortality. Breast Cancer Res. 2004;6(6):229-39.

29. Ferlay J, Shin HR, Bray F, Forman D, Mathers C, Parkin DM. Estimates of worldwide burden of cancer in 2008: GLOBOCAN 2008. Int J Cancer. 2010; 127(12):2893-917.

30. Chouchane L, Boussen H, Sastry KS. Breast cancer in Arab populations: molecular characteristics and disease management implications. Lancet Oncol. 2013;14(10):e417-24.

31. Labib, al: Report of the CARE project (CAncer Registration over all Egypt) conducted by the Ministry of health and population. In.; 2006.

32. Mourali N, Muenz LR, Tabbane F, Belhassen S, Bahi J, Levine PH. Epidemiologic features of rapidly progressing breast cancer in Tunisia. Cancer. 1980:46(12):2741-6.

33. International HapMap Consortium. The International HapMap Project. Nature. 2003:426(6968):789-96.

34. Auton A, Brooks LD, Durbin RM, Garrison EP, Kang HM, Korbel JO, Marchini JL, McCarthy S, McVean GA, Abecasis GR. A global reference for human genetic variation. Nature. 2015;526(7571):68-74.

35. Stranger BE, Stahl EA, Raj T. Progress and promise of genome-wide association studies for human complex trait genetics. Genetics. 2011;187(2):367-83.

36. Freedman ML, Monteiro AN, Gayther SA, Coetzee GA, Risch A, Plass C, Casey G, De Biasi M, Carlson C, Duggan D, et al. Principles for the post-GWAS functional characterization of cancer risk loci. Nat Genet. 2011;43(6):513-8.

37. McCarthy MI, Hirschhorn JN. Genome-wide association studies: potential next steps on a genetic journey. Hum Mol Genet. 2008;17(R2):R156-65.

38. Teo YY, Small KS, Kwiatkowski DP. Methodological challenges of genomewide association analysis in Africa. Nat Rev Genet. 2010;11(2):149-60.

39. Maxwell KN, Nathanson KL. Common breast cancer risk variants in the postCOGS era: a comprehensive review. Breast Cancer Res. 2013;15(6):212.

40. Edwards SL, Beesley J, French JD, Dunning AM. Beyond GWASs: illuminating the dark road from association to function. Am J Hum Genet. 2013;93(5): 779-97.

41. Udler MS, Meyer KB, Pooley KA, Karlins E, Struewing JP, Zhang J, Doody DR, MacArthur S, Tyrer J, Pharoah PD, et al. FGFR2 variants and breast cancer risk: fine-scale mapping using African American studies and analysis of chromatin conformation. Hum Mol Genet. 2009;18(9):1692-703.

42. Henn BM, Botigue LR, Gravel S, Wang W, Brisbin A, Byrnes JK, Fadhlaoui-Zid K, Zalloua PA, Moreno-Estrada A, Bertranpetit J, et al. Genomic ancestry of North Africans supports back-to-Africa migrations. PLoS Genet. 2012;8(1): e1002397.

43. Ben Halim N, Ben Alaya Bouafif N, Romdhane L, Kefi Ben Atig R, Chouchane I, Bouyacoub Y, Arfa I, Cherif W, Nouira S, Talmoudi F, et al. consanguinity, 
endogamy, and genetic disorders in Tunisia. J Community Genet. 2013;4(2): 273-84.

44. Troudi W, Uhrhammer N, Sibille C, Dahan C, Mahfoudh W, Bouchlaka Souissi C, Jalabert T, Chouchane L, Bignon YJ, Ben Ayed F, et al. Contribution of the BRCA1 and BRCA2 mutations to breast cancer in Tunisia. J Hum Genet. 2007;52(11):915-20.

45. Fourati A, Louchez MM, Fournier J, Gamoudi A, Rahal K, El May MV, El May A, Revillion F, Peyrat JP. Screening for common mutations in BRCA1 and BRCA2 genes: interest in genetic testing of Tunisian families with breast and/or ovarian cancer. Bull Cancer. 2014;101(11):E36-40.

46. Shan J, Mahfoudh W, Dsouza SP, Hassen E, Bouaouina N, Abdelhak S, Benhadjayed A, Memmi H, Mathew RA, Aigha II, et al. Genome-wide association studies (GWAS) breast cancer susceptibility loci in Arabs: susceptibility and prognostic implications in Tunisians. Breast Cancer Res Treat. 2012;135(3):715-24.

47. Miller SA, Dykes DD, Polesky HF. A simple salting out procedure for extracting DNA from human nucleated cells. Nucleic Acids Res. 1988;16(3):1215.

48. Scharpf RB, Irizarry RA, Ritchie ME, Carvalho B, Ruczinski I. Using the R package crlmm for genotyping and copy number estimation. J Stat Softw. 2011:40(12):1-32.

49. Gonzalez JR, Armengol L, Sole X, Guino E, Mercader JM, Estivill X, Moreno V. SNPassoc: an $\mathrm{R}$ package to perform whole genome association studies. Bioinformatics (Oxford, England). 2007;23(5):644-5.

50. Barrett JC, Fry B, Maller J, Daly MJ. Haploview: analysis and visualization of LD and haplotype maps. Bioinformatics (Oxford, England). 2005;21(2):263-5.

51. Gabriel SB, Schaffner SF, Nguyen H, Moore JM, Roy J, Blumenstiel B, Higgins J, DeFelice M, Lochner A, Faggart M, et al. The structure of haplotype blocks in the human genome. Science (New York, NY). 2002;296(5576):2225-9.

52. Stephens M, Smith NJ, Donnelly P. A new statistical method for haplotype reconstruction from population data. Am J Hum Genet. 2001;68(4):978-89.

53. Tavtigian SV, Greenblatt MS, Lesueur F, Byrnes GB. In silico analysis of missense substitutions using sequence-alignment based methods. Hum Mutat. 2008;29(11):1327-36.

54. Ng PC, Henikoff S. Predicting deleterious amino acid substitutions. Genome Res. 2001;11(5):863-74.

55. Boyle AP, Hong EL, Hariharan M, Cheng Y, Schaub MA, Kasowski M, Karczewski KJ, Park J, Hitz BC, Weng S, et al. Annotation of functional variation in personal genomes using RegulomeDB. Genome Res. 2012;22(9):1790-7.

56. Yang TP, Beazley C, Montgomery SB, Dimas AS, Gutierrez-Arcelus M, Stranger BE, Deloukas P, Dermitzakis ET. Genevar: a database and Java application for the analysis and visualization of SNP-gene associations in eQTL studies. Bioinformatics (Oxford, England). 2010;26(19):2474-6.

57. Ferlay J, Soerjomataram I, Dikshit R, Eser S, Mathers C, Rebelo M, Parkin DM, Forman D, Bray F. Cancer incidence and mortality worldwide: sources, methods and major patterns in GLOBOCAN 2012. Int J Cancer. 2015;136(5):E359-86.

58. Chalabi N, Bernard-Gallon DJ, Bignon YJ, Kwiatkowski F, Agier M, Vidal V, Laplace-Chabaud V, Sylvain-Vidal V, Bertholet V, De Longueville F, et al. Comparative clinical and transcriptomal profiles of breast cancer between French and South Mediterranean patients show minor but significative biological differences. Cancer Genomics Proteomics. 2008;5(5):253-61.

59. Medimegh I, Troudi W, Omrane I, Ayari H, Uhrhummer N, Majoul H, Benayed F, Mezlini A, Bignon YJ, Sibille C, et al. Consanguinity protecting effect against breast Cancer among Tunisian women: analysis of BRCA1 haplotypes. Asian Pac J Cancer Prev. 2015;16(9):4051-5.

60. Mahfoudh W, Bouaouina N, Ahmed SB, Gabbouj S, Shan J, Mathew R, Uhrhammer N, Bignon YJ, Troudi W, Elgaaied AB, et al. Hereditary breast cancer in middle eastern and North African (MENA) populations: identification of novel, recurrent and founder BRCA1 mutations in the Tunisian population. Mol Biol Rep. 2012;39(2):1037-46.

61. Riahi A, Kharrat M, Ghourabi ME, Khomsi F, Gamoudi A, Lariani I, May $A E$, Rahal K, Chaabouni-Bouhamed H. Mutation spectrum and prevalence of BRCA1 and BRCA2 genes in patients with familial and early-onset breast/ovarian cancer from Tunisia. Clin Genet. 2015;87(2): 155-60.

62. Medimegh I, Troudi W, Stambouli N, Khodjet-El-Khil H, Baroudi O, Ayari H, Omrane I, Uhrhammer N, Privat M, Mezlini A, et al. Wild-type genotypes of BRCA1 gene SNPs combined with micro-RNA over-expression in mammary tissue leading to familial breast cancer with an increased risk of distant metastases' occurrence. Med Oncol (Northwood, London, England). 2014; 31(11):255.
63. Kefi R, Hsouna S, Ben Halim N, Lasram K, Romdhane L, Messai H, Abdelhak S. Phylogeny and genetic structure of Tunisians and their position within Mediterranean populations. Mitochondrial DNA. 2015;26(4):593-604.

64. Ben Halim N, Dorboz I, Kefi R, Kharrat N, Eymard-Pierre E, Nagara M, Romdhane L, Ben Alaya-Bouafif N, Rebai A, Miladi N, et al. Determination of arylsulfatase a pseudodeficiency allele and haplotype frequency in the Tunisian population. Neurol Sci. 2016;37(3):403-9.

65. Ennafaa H, Fregel R, Khodjet-El-Khil H, Gonzalez AM, Mahmoudi HA, Cabrera VM, Larruga JM, Benammar-Elgaaied A. Mitochondrial DNA and Ychromosome microstructure in Tunisia. J Hum Genet. 2011;56(10):734-41.

66. Fadhlaoui-Zid K, Martinez-Cruz B, Khodjet-el-khil H, Mendizabal I, BenammarElgaaied A, Comas D. Genetic structure of Tunisian ethnic groups revealed by paternal lineages. Am J Phys Anthropol. 2011;146(2):271-80.

67. Cherni L, Fernandes V, Pereira JB, Costa MD, Goios A, Frigi S, YacoubiLoueslati B, Amor MB, Slama A, Amorim A, et al. Post-last glacial maximum expansion from Iberia to North Africa revealed by fine characterization of mtDNA H haplogroup in Tunisia. Am J Phys Anthropol. 2009;139(2):253-60.

68. Ruiz-Narvaez EA, Rosenberg L, Yao S, Rotimi CN, Cupples AL, Bandera EV, Ambrosone CB, Adams-Campbell LL, Palmer JR. Fine-mapping of the $6 \mathrm{q} 25$ locus identifies a novel SNP associated with breast cancer risk in AfricanAmerican women. Carcinogenesis. 2013;34(2):287-91.

69. Long J, Zhang B, Signorello LB, Cai Q, Deming-Halverson S, Shrubsole MJ, Sanderson M, Dennis J, Michailidou K, Easton DF, et al. Evaluating genomewide association study-identified breast cancer risk variants in AfricanAmerican women. PLoS One. 2013;8(4):e58350.

70. Hamdi Y, Soucy P, Adoue V, Michailidou K, Canisius S, Lemacon A, Droit A, Andrulis IL, Anton-Culver $\mathrm{H}$, Arndt $\mathrm{V}$, et al. Association of breast cancer risk with genetic variants showing differential allelic expression: identification of a novel breast cancer susceptibility locus at 4q21. Oncotarget. 2016;7(49): 80140-63.

71. Chen F, Chen GK, Millikan RC, John EM, Ambrosone CB, Bernstein L, Zheng W, Hu JJ, Ziegler RG, Deming SL, et al. Fine-mapping of breast cancer susceptibility loci characterizes genetic risk in African Americans. Hum Mol Genet. 2011;20(22):4491-503.

72. Xiao ZD, Liu X, Zhuang L, Gan B. NBR2: a former junk gene emerges as a key player in tumor suppression. Mol Cell Oncol. 2016;3(4):e1187322.

73. Luo S, Lu JY, Liu L, Yin Y, Chen C, Han X, Wu B, Xu R, Liu W, Yan P, et al. Divergent IncRNAs regulate gene expression and lineage differentiation in pluripotent cells. Cell Stem Cell. 2016;18(5):637-52.

74. Hung CL, Wang LY, Yu YL, Chen HW, Srivastava S, Petrovics G, Kung HJ. A long noncoding RNA connects C-Myc to tumor metabolism. Proc Natl Acad Sci U S A. 2014;111(52):18697-702.

75. Xiao ZD, Zhuang L, Gan B. Long non-coding RNAs in cancer metabolism. BioEssays. 2016;38(10):991-6.

76. Salmena L, Poliseno L, Tay Y, Kats L, Pandolfi PP. A ceRNA hypothesis: the Rosetta stone of a hidden RNA language? Cell. 2011;146(3):353-8.

77. Pastrello C, Tsay M, McQuaid R, Abovsky M, Pasini E, Shirdel E, Angeli M, Tokar T, Jamnik J, Kotlyar M, et al. Circulating plant miRNAs can regulate human gene expression in vitro. Sci Rep. 2016;6:32773.

78. Chin AR, Fong MY, Somlo G, Wu J, Swiderski P, Wu X, Wang SE. Crosskingdom inhibition of breast cancer growth by plant miR159. Cell Res. 2016; 26(2):217-28.

79. Wang K, Li H, Yuan Y, Etheridge A, Zhou Y, Huang D, Wilmes P, Galas D. The complex exogenous RNA spectra in human plasma: an interface with human gut biota? PLoS One. 2012;7(12):e51009.

80. Cox DG, Simard J, Sinnett D, Hamdi Y, Soucy P, Ouimet M, Barjhoux L, Verny-Pierre C, McGuffog L, Healey S, et al. Common variants of the BRCA1 wild-type allele modify the risk of breast cancer in BRCA1 mutation carriers. Hum Mol Genet. 2011;20(23):4732-47. 